\title{
Role of resilience and social support in alleviating depression in patients receiving maintenance hemodialysis
}

This article was published in the following Dove Press journal:

Therapeutics and Clinical Risk Management

\author{
Yueh-Min Liu' \\ Hong-Jer Chang ${ }^{2}$ \\ Ru-Hwa Wang ${ }^{3}$ \\ Li-King Yang ${ }^{4}$ \\ Kuo-Cheng $\mathrm{Lu}^{4}$ \\ $\mathrm{Yi}-\mathrm{Chou} \mathrm{Hou}{ }^{4}$
}

'Department of Nursing, Ching Kuo Institute of Management and Health, Taiwan; ${ }^{2}$ Graduate Institute of LongTerm Care, National Taipei University of Nursing and Health Sciences, Taipei City, Taiwan; ${ }^{3}$ Department of Nursing, Fu-Jen Catholic University, New Taipei City, Taiwan; ${ }^{4}$ Division of Nephrology, Department of Medicine, Cardinal Tien Hospital, School of Medicine, Fu-Jen Catholic University, New Taipei, Taiwan
Correspondence: Yi-Chou Hou Division of Nephrology, Department of Medicine, Cardinal Tien Hospital, School of Medicine, Fu-Jen Catholic University, 23। 48 No 362, Zhongzheng Road, Xindian District, New Taipei City, Taiwan Tel +8860222123066

Email athletics910@gmail.com
Background: Patients who undergo hemodialysis encounter challenges including role changes, physical degeneration, and difficulty in performing activities of daily living (ADLs) and self-care. These challenges deteriorate their physiological and psychosocial conditions, resulting in depression. High resilience (RES) and social support can alleviate stress and depression. This study evaluated the importance of RES and social support in managing depression in elderly patients undergoing maintenance hemodialysis (HD).

Patients and methods: In this descriptive, correlational study, 194 older patients undergoing HD were enrolled from the HD centers of three hospitals in northern Taiwan. The Barthel ADL Index, RES scale, Inventory of Socially Supportive Behavior, and Beck Depression Inventory-II were used. Hierarchical regression analysis was applied to evaluate the interaction of RES and social support with illness severity, demographics, and ADLs.

Results: Of the total participants, $45.9 \%$ experienced depressive symptoms. Demographic analysis showed that men and those with high educational level and income and financial independence had less depression $(p<0.01)$. Patients with a higher Barthel Index $(\mathrm{n}=103)$, RES scale ( $\mathrm{n}=33)$, and social support $(\mathrm{n}=113)$ showed less depressive symptoms $(p<0.01)$. We found a significant negative correlation between depressive symptoms and social support $(r=-0.506, p<0.01)$ and RES $(r=-0.743, p<0.01)$. Hierarchical regression analysis showed that RES could buffer the effects of symptom severity on depression $(b=-0.436, p<0.01)$, but social support did not exert a buffering effect.

Conclusion: The severity of illness symptoms and ADLs were the major determinants of depressive symptoms. High RES could alleviate depressive symptoms in the older patients undergoing HD.

Keywords: depressive symptom, resilience, social support, older hemodialysis patient

\section{Introduction}

End-stage renal disease (ESRD) is a typical chronic, irreversible, life-threatening illness. Long-term hemodialysis (HD), continuous ambulatory peritoneal dialysis, and kidney transplant usually prolong the survival of patients with ESRD. According to the Taiwan Chronic Kidney Disease Clinical Guidelines, the incidence of patients in Taiwan who received dialysis was 450 per million population in $2011 .{ }^{1}$ In $2014,62,408$ people received HD as treatment for ESRD. The lifetime cost of each HD patient is US\$185,235 $\pm 9,623$ in Taiwan, and the annual cost of HD accounts for $5.86 \%-6.31 \%$ of annual National Health Insurance spending. ${ }^{1,3}$ Lower socioeconomic status not only reflects the poorer quality of life of patients who receive HD, but also predicts their increased medical complications and psychological stress. ${ }^{4-7}$ To maintain the quality 
of HD treatment for improving the health of patients with ESRD belonging to different socioeconomic classes, Taiwan has developed a well-established system for HD treatment by economic support from national health insurance. ${ }^{8}$ The established economic systemic provides a circumference of adequate social support for the ESRD patients.

However, the patients receiving maintenance HD suffered huge mental stress from different aspects. In $2014,50.40 \%$ of patients who received HD in Taiwan were aged $\geq 65$ years. $^{2}$ The incidence of depression was higher in patients who received HD than in patients with chronic kidney disease alone. ${ }^{9}$ Physical symptoms occurred during or after HD treatment, such as fatigue, cold aversion, pruritus, lower torso weakness, muscle cramping, and difficulty sleeping., ${ }^{4,10,11}$ These physical symptoms are caused by various factors, such as the accumulation of uremic toxin, chronic inflammation, comorbidities, aging, and increased catabolism due to HD treatment. ${ }^{12,13}$ These physical symptoms are associated with depression, and a higher burden of these physical symptoms has been correlated with a higher severity of depression and a poorer quality of life. ${ }^{14,15}$ In addition to the suffering and helplessness, older patients who receive HD also encounter challenges such as role change, physical degeneration, and difficulty in performing activities of daily living (ADLs) and self-care, which further deteriorate their physiological and psychosocial conditions. ${ }^{16}$ The severe interference in living capabilities leads to depression, and the induced negative thoughts result in withdrawal from the treatment and even suicide. ${ }^{17}$ Approximately $25 \%-50 \%$ of patients who underwent dialysis experience moderate to severe depressive symptoms. ${ }^{18,19}$ Among patients who received HD, the adjusted relative risk of death or first hospitalization within 1 year increased in those with physician-diagnosed depression. ${ }^{20}$ Therefore, mitigating depression is a crucial issue for patients with ESRD.

In order to confront the mental stress and depression during the treatment, internal adaptation for stress and external support from the society play important roles for individuals to overcome their depression. Resilience (RES), defined as the process of adapting appropriately in the face of adversity, trauma, tragedy, threats, or significant sources of stress or "bouncing back" from difficult experiences, is a personal trait or an adaptive process that can be developed. ${ }^{21,22}$ When chronic kidney disease (CKD) progresses to ESRD, patients must receive dialysis treatment to survive, and they are often prone to emotions such as helplessness, depression, and fear. ${ }^{23}$ Social support, defined as information leading individuals to believe that they are cared for, loved, esteemed, and members of a network of mutual obligations, is provided by caregivers, medical staff, and the social welfare system. ${ }^{24}$ The emotional, instrumental, and financial products for individuals are beneficial in terms of both the health outcomes and psychological stress. ${ }^{25}$ It has been well known that the provision of effective social support to patients with ESRD helps them better understand their own illness and adhere to their treatment and nutrition. ${ }^{26}$ Psychologically, social support plays a protective role in alleviating depression and achieving a better quality of life. ${ }^{27,28}$ Therefore, social support is helpful for patients to confront their illness. RES is also defined as the ability of an individual to successfully endure and adapt to stress, challenges, or environmental changes. ${ }^{29,30}$ Increased RES plays a vital role in eliminating the stress encountered in illnesses; it also reduces physical disability and ameliorates stress-related damages. ${ }^{29,31}$ Health-promoting behavior has been applied to enhance RES in patients with CKD, and better RES can help them confront stress and depression, enabling them to lead a positive life. ${ }^{32}$ Therefore, RES might be essential for patients undergoing HD to relieve the depression and stress caused by the illness.

The aforementioned studies have indicated that disability in performing ADLs causes physical and mental stress in patients undergoing HD, and such disability has been associated with depression. Social support and RES have been reported as important for buffering depression in other diseases. However, very little attention has been focused on physical symptoms and depression in patients who receive HD. There is a lack of studies exploring the effect of RES and social support on physical symptoms and depression in Taiwan. Therefore, in the current study, we evaluated the severity of depression in elderly patients who received HD and the risk factors for depression. Furthermore, we examined whether RES and social support reduce the severity of depression in older patients who received HD.

\section{Patients and methods Study design}

A descriptive, correlational research design was used in this study.

\section{Patients and setting}

We recruited 194 patients from the HD centers of three hospitals in northern Taiwan as research participants through purposive sampling. Patients' selection criteria were as follows: 1) outpatients with an HD history of $\geq 3$ months, 2) age $>60$ years, 3) understood Mandarin or Taiwanese (verbally) and capable to clearly answer relevant questions, 
4) a score of $\geq 8$ in the Short Portable Mental Status Questionnaire (a 10-item questionnaire including questions regarding recent and distant memory; respondents with an error of $<2$ are defined to have intact cognitive function), ${ }^{33}$ and 5) willing to participate in this study. The measurement was performed by a well-trained nurse in the HD center. The questionnaire was obtained from the participants before the session of HD. Written informed consent of all the participants was obtained during the HD treatment with privacy.

\section{Instruments}

In this study, we used a structured questionnaire that contained questions regarding demographic characteristics, illness severity symptoms, and laboratory variables; question on ADLs; the RES scale; the social support scale; and the Beck Depression Inventory-II (BDI-II). For the illiterate participants who could not read the questionnaire, we read out the questionnaire.

\section{Demographics, illness severity symptoms, and laboratory variables}

Demographic data included patients' self-reported age, gender, educational level, marital status, monthly income, welfare status, income source, religion, living with family or not, and the main caregiver. The underlying etiologies for ESRD (diabetes mellitus, hypertension, chronic glomerulonephritis, and polycystic kidney disease) and comorbidities (including respiratory disorders, heart disorders, stroke, arthritis, and cancer) were confirmed on the basis of their medical records. Additionally, the patients' HD history, physical symptoms, and laboratory variables (ie, hemoglobin and albumin levels) were reviewed. The Chinese version of the 10-item Physical Symptom Distress Checklist was used to assess the severity of physical symptoms. ${ }^{34}$ The score range of each item was as follows: no symptoms (0), mild (1), moderate (2), and severe (3). Higher scores indicated that the symptoms caused higher distress. In addition to the symptoms included in the checklist, "involuntary tremors of the extremities" was included as the 11th symptom according to a nephrologist's suggestion. The estimated Cronbach's $\alpha$ of this checklist was 0.64 .

\section{Activities of daily living}

The ADLs of older patients were evaluated using the Barthel ADL Index and the Lawton's Instrumental ADL (IADL) scale, which has been the most widely used for objectively assessing the ADL status. The Barthel ADL Index includes 10 items, with the index scores of $0-20,21-60,61-90,91-99$, and 100 indicating totally dependent, maximally dependent, moderately dependent, minimally dependent, and independent, respectively. The internal consistency reliability of the Barthel ADL Index was high with a Cronbach's $\alpha$ of $0.89 .{ }^{35}$ The Cronbach's $\alpha$ of the Barthel ADL Index in this study was 0.87 . The Lawton's IADL scale is commonly used to measure functioning among older adults. This scale includes eight items that are rated on a scale ranging from 0 (unable to function) to 1 (normal function). Total scores range from 0 to 8 , with lower scores indicating lower functioning. A score of 8 in the Lawton's IADL scale indicates complete independence. A score $<8$ is defined as representing dependence. The Cronbach's $\alpha$ of the Chinese version of the Lawton's IADL scale was 0.92 in Chuang's study, ${ }^{36}$ whereas it was 0.94 in the current study.

\section{RES scale}

We used the Chinese version of the 25-item Wagnild's Resilience Scale, ${ }^{21}$ which was extracted from Li's study ${ }^{37}$ with measurement by using Seven-category Likert scale with total scores ranging from 25 to 175 . Individuals scoring 147-175, $127-146$, and $<120$ are considered to have better, moderate, and low resilience, respectively. The Cronbach's $\alpha$ of this scale was 0.91 in a previous study and 0.97 in the current study, indicating that this scale showed high internal consistency in both the studies. Ahern et $\mathrm{al}^{38}$ proposed that the RES scale is the most appropriate tool for assessing psychometric properties in different age groups.

\section{Social support scale}

The social support scale used in this study was adopted from the study of Tseng. ${ }^{39}$ The scale was used to determine social support for 100 patients with depression in the outpatient department, and this scale has shown satisfactory reliability (Cronbach's $\alpha=0.95$ ). This scale contains 15 items based on emotional support, appraisal support, informational support, and tangible support; the overall score ranges from 15 to 60 . A higher score indicates a higher degree of social support. The Cronbach's $\alpha$ of the social support scale in this study was 0.88 .

\section{Beck Depression Inventory-II}

The BDI-II contains 21 questions, and each answer is scored on a scale ranging from 0 to 3 . The ranking for the severity of depression is as follows: 0-13 (minimal depression), 14-19 (mild depression), 20-28 (moderate depression), and 29-63 (severe depression). Higher total scores indicate more severe depressive symptoms. The BDI-II is positively correlated 
with the Hamilton Depression Rating Scale with a Pearson's $r$ of 0.71 , which indicates close agreement. The BDI-II also has high internal consistency (Cronbach's $\alpha=0.91$ ). The Chinese version of the BDI-II (Chinese Behavioral Science Corporation) has been used in studies to evaluate the depressive symptoms of patients undergoing dialysis and has shown acceptable reliability and validity. Liu and Chen used this scale to evaluate 52 patients who underwent HD and reported a Cronbach's $\alpha$ of 0.87 . The Cronbach's $\alpha$ of this study was also $0.87 . .^{34}$

\section{Ethical considerations}

This study was approved by the Institutional Review Board of Cardinal Tien Hospital in Taiwan (CTH-98-3-5-007). We then obtained the administrative recognition from three hospitals in northern Taiwan and recruited 200 older patients undergoing HD according to the selection criteria. Written informed consent was obtained from all participants after informing them about the purpose, procedure, and measures of this study. For the illiterate participants, the informed consent was completed by their relatives, and the process for obtaining written informed consent was approved by the Institutional Review Board. The participants were free to withdraw from the study at any time.

\section{Data analysis}

Continuous variables are expressed as mean \pm SDs, and categorical values as percentages. We tested the normal distribution of samples by using the Kolmogorov-Smirnov test and compared the patients' educational level, marital status, welfare status, and income source by using the Student's $t$-test. Analysis of variance was used to compare the severity of depression between different caregivers. Pearson's correlation coefficient tests were applied to evaluate the correlations of depressive symptoms with monthly allowance, HD duration, ADL, IADL status, RES, social support, and physical symptoms during HD for the entire study population. Hierarchical regression analysis was used to verify the buffering effect of social support and RES on stressors and depression arising from an illness. A three-step model was applied. In the first-step model, we added the demographic data. In the second-step model, we added the data regarding illness and ADLs. In the third-step model, we added the RES or social support data to evaluate their buffering effect on depression. All tests were two sided, and $p<0.05$ was considered statistically significant. All statistical analyses were performed using SPSS for Windows (Version X; SPSS, Inc., Chicago, IL, USA).

\section{Results Demographic data}

The demographic data of the participants are listed in Table 1. A total of 200 participants were enrolled, of which 3 did not meet the inclusion criteria, 2 were lost to follow-up, and 1 could not answer the questionnaire. Finally, the data from 194 participants were analyzed. The dropout rate in this study was $3 \%$. The mean age of the participants was $72.64 \pm 8.58$ years. Of the total analyzed participants, $81 \%$ were illiterate and $56.7 \%$ were women. Most of the participants $(61.3 \%)$ were married and in cohabitation, $\sim 92 \%$ of the participants lived with family, the main caregivers were children or children-in-law $(32.5 \%)$ or spouses $(32 \%)$, and only $3.6 \%$ lived in institutions (eg, nursing homes; Table 1). Of the total participants, $35.6 \%$ and $33.0 \%$ had monthly allowances of $\leq$ New Taiwan Dollar (NT\$) 10,000 and NT\$10,000-20,000, respectively; this finding indicated that the monthly allowance of most older patients $(68.6 \%)$ was $<$ NT\$20,000. Regarding the income source, 30.9\% of the participants relied on their own savings, indicating that $69.1 \%$ of the elderly patients required financial support from others, mostly from their children (53.1\%).

The symptom occurring during HD that exerted the most adverse effect on daily life was fatigue $(71.1 \%)$, followed by muscle weakness (64.4\%) and itchiness (63.4\%), whereas involuntary tremors of the extremities caused the least distress (10.3\%). The following laboratory variables were recorded: hemoglobin, $10 \pm 1.53 \mathrm{~g} / \mathrm{dL}$; albumin, $3.91 \pm 0.39 \mathrm{~g} / \mathrm{dL}$; and dialysis efficiency calculator $(\mathrm{Kt} / \mathrm{V}), 1.67 \pm 0.93$.

The average BDI-II score of the participants for depressive symptoms was 13.43 ( $\mathrm{SD}=9.51$ ), and the percentage of the participants without depression was the highest $(54.1 \%)$, followed by those of patients with mild depression $(21.6 \%)$, moderate depression (16.5\%), and severe depression $(7.7 \%)$. The average score of the participants for ADL was $87.56(\mathrm{SD}=19.06)$. On the basis of the functional level, $53.1 \%, 28.4 \%, 10.8 \%, 6.7 \%$, and $1.0 \%$ of the participants were determined to be completely independent, moderately independent, severely dependent, slightly dependent, and completely dependent, respectively. This result indicated that most of the patients were slightly dependent for their ADL. The average score in Lawton's IADL scale was 13.45 $(\mathrm{SD}=8.05)$, and the results revealed that $17 \%$ and $83 \%$ of the older patients were independent and required assistance, respectively. The average score of the participants in the RES scale was $116.72(\mathrm{SD}=31.52) ; 46.4 \%, 36.6 \%$, and only $17 \%$ of the participants had low, moderate, and high RES, respectively (Table 2). The average score of the participants in the 
Table I Demographic data of the participants $(\mathrm{N}=194)$

\begin{tabular}{|c|c|c|c|}
\hline Variable & $\mathbf{n}$ & $\%$ & $\mathbf{M} \pm \mathbf{S D}$ \\
\hline \multicolumn{4}{|l|}{ Age (years) } \\
\hline $60-64$ & 44 & 23 & $72.64 \pm 8.58$ \\
\hline $65-96$ & 150 & 77 & \\
\hline \multicolumn{4}{|l|}{ Gender } \\
\hline Male & 84 & 43 & \\
\hline Female & 110 & 57 & \\
\hline \multicolumn{4}{|l|}{ Education } \\
\hline Literate & 37 & 19 & \\
\hline Illiterate & 157 & 81 & \\
\hline \multicolumn{4}{|l|}{ Living with family } \\
\hline Yes & 179 & 92.3 & \\
\hline No & 15 & 7.7 & \\
\hline \multicolumn{4}{|l|}{ Primary caregiver } \\
\hline Spouse & 62 & 32 & \\
\hline Child/child-in-law & 63 & 32.5 & \\
\hline Relatives/friends/employee & 29 & 14.9 & \\
\hline Institution/nursing home & 7 & 3.6 & \\
\hline Oneself & 33 & 17 & \\
\hline \multicolumn{4}{|l|}{ Monthly income allowance } \\
\hline$<$ NT\$10,000 & 69 & 35.6 & \\
\hline NT\$10,000-20,000 & 64 & 33 & \\
\hline NT $\$ 20,000-30,000$ & 28 & 14.4 & \\
\hline$>\mathrm{NT} \$ 30,000$ & 33 & 17 & \\
\hline \multicolumn{4}{|l|}{ Income sources } \\
\hline Oneself & 60 & 30.9 & \\
\hline Spouse & 15 & 7.7 & \\
\hline Children & 103 & 53.1 & \\
\hline Others & 16 & 8.2 & \\
\hline \multicolumn{4}{|l|}{ Physical symptoms } \\
\hline Fatigue & 138 & 71.1 & \\
\hline Muscle weakness & 125 & 64.4 & \\
\hline Skin itchiness & 123 & 63.4 & \\
\hline \multicolumn{4}{|l|}{ Laboratory variables } \\
\hline Hemoglobin (g/dL) & & & $10.24 \pm 1.53$ \\
\hline Albumin $(\mathrm{g} / \mathrm{dL})$ & & & $3.91 \pm 0.39$ \\
\hline $\mathrm{Kt} / \mathrm{V}$ & & & $1.67 \pm 0.93$ \\
\hline \multicolumn{4}{|l|}{ ADL } \\
\hline 100 & 103 & 53.1 & $87.56 \pm 19.05$ \\
\hline $91-99$ & 13 & 6.7 & \\
\hline $61-90$ & 55 & 28.4 & \\
\hline $21-60$ & 21 & 10.8 & \\
\hline $0-20$ & 2 & 1.0 & \\
\hline \multicolumn{4}{|l|}{ IADL } \\
\hline Independent & 33 & 17 & $13.45 \pm 8.04$ \\
\hline Dependent & 161 & 83 & \\
\hline \multicolumn{4}{|l|}{ Resilience } \\
\hline |47-175 (high) & 33 & 17 & $116.72 \pm 31.52$ \\
\hline$|2|-\mid 46$ (moderate) & 71 & 36.6 & \\
\hline$<120$ (low) & 90 & 46.4 & \\
\hline \multicolumn{4}{|l|}{ Social support } \\
\hline 46-60 (high) & 113 & 58.2 & $47.14 \pm 9.32$ \\
\hline $31-45$ (moderate) & 70 & 36.1 & \\
\hline 15-30 (low) & 11 & 5.7 & \\
\hline \multicolumn{4}{|l|}{ BDI-II scale } \\
\hline 0-13 (minimal) & 105 & 54.1 & $|3.43 \pm 9.5|$ \\
\hline $14-19$ (mild) & 42 & 21.6 & \\
\hline 20-28 (moderate) & 32 & 16.5 & \\
\hline
\end{tabular}

Abbreviations: ADL, activity of daily living; BDI, Beck Depression Inventory; IADL, instrumental activity of daily living; NT\$, New Taiwan Dollar.
Table 2 Association between the severity of depression and demographic characteristics ( $\mathrm{N}=194)$

\begin{tabular}{|c|c|c|c|c|}
\hline Variable & n (\%) & $\mathbf{M} \pm \mathbf{S D}$ & $t$-test & F-test \\
\hline \multicolumn{5}{|l|}{ Age (years) } \\
\hline $60-64$ & $44(23)$ & $72.64 \pm 8.58$ & & 2.173 \\
\hline $65-96$ & I50 (77) & & & \\
\hline \multicolumn{5}{|l|}{ Gender } \\
\hline Male & $84(43.3)$ & $11.3 \pm 9.3$ & $2.726^{* *}$ & \\
\hline Female & $110(56.7)$ & $15.0 \pm 9.3$ & & \\
\hline \multicolumn{5}{|l|}{ Education } \\
\hline Literate & 157 (80.9) & $12.6 \pm 9.5$ & $2.668^{* *}$ & \\
\hline Illiterate & $37(19.1)$ & $16.5 \pm 8.6$ & & \\
\hline \multicolumn{5}{|l|}{ Living with family } \\
\hline Yes & $179(92.3)$ & $13.3 \pm 9.49$ & 0.286 & \\
\hline No & $15(7.7)$ & $14.1 \pm 9.97$ & & \\
\hline \multicolumn{5}{|l|}{ Primary caregiver } \\
\hline Spouse & $62(32)$ & $13.0 \pm 10.32$ & & $3.299 * *$ \\
\hline Child/child-in-law & $63(32.5)$ & $13.3 \pm 7.94$ & & \\
\hline Relatives/friends & $4(2)$ & $11.5 \pm 6.13$ & & \\
\hline Employee & $25(12.9)$ & $16.4 \pm 10.00$ & & \\
\hline Institution/nursing home & $7(3.6)$ & $24.0 \pm 6.97$ & & \\
\hline Oneself & $33(17)$ & $10.0 \pm 9.36$ & & \\
\hline \multicolumn{5}{|l|}{ Monthly income allowance } \\
\hline$<\mathrm{NT} \$ 30,000$ & $16 \mid(83)$ & $14.23 \pm 9.93$ & & $4.25 I^{* * *}$ \\
\hline$>\mathrm{NT} \$ 30,000$ & $33(17)$ & $8.79 \pm 7.54$ & & \\
\hline
\end{tabular}

Note: $* * p<0.01$.

Abbreviation: NT\$, New Taiwan Dollar.

social support scale was $47.14 \pm 9.32$, with $58.2 \%$ and $36.1 \%$ receiving high and moderate social support, respectively. This result indicated that the older patients undergoing HD mostly received above average social support.

\section{Association between the severity of depression and demographic characteristics}

Table 2 shows the differences in the severity of depression according to demographic characteristics. A significant difference was found between gender and depressive symptoms $(t=2.726, p<0.01)$. Depressive symptoms were higher in women than in men (Table 2). A significant difference was also observed in the depressive symptoms of patients with different educational levels $(t=2.668, p<0.01)$; illiterate participants exhibited higher depressive symptoms than literate participants. The results of the analysis of variance test revealed a significant difference in depressive symptoms for different monthly allowances $(F=4.251, p<0.01)$; patients with monthly allowances of $>$ NT $\$ 30,000$ exhibited fewer depressive symptoms than those with monthly allowances of $<$ NT $\$ 30,000$. The income source also significantly varied with depressive symptoms $(F=2.972, p<0.05)$. Patients who obtained an income from themselves, the government, 
relatives, or friends experienced fewer depressive symptoms than those who obtained an income only from other donations. Regarding the primary caretaker, patients who took care of themselves had fewer depressive symptoms than those who depended on other person'r assistance $(F=3.299, p<0.01)$.

\section{Correlations between illness, physical symptoms, ADLs, RES, social support, and depression}

The correlations between illness, physical symptoms, ADLs, RES, social support, and depression are shown in Table 3. A total of 10 diseases, including diabetes, heart disease, hypertension, and stroke, were considered as combined chronic illnesses in this study. The average number of combined chronic diseases in the older patients with ESRD was 1.64 , with the highest percentage of the patients having hypertension $(54.6 \%)$, followed by diabetes $(48.5 \%)$ and heart attack (20.1\%; not listed). The severity of physical symptoms positively correlated with the severity of depression ( $r=0.42, p<0.001)$, indicating that depression increased with the severity of physical symptoms.

The participants were individually examined and scored for their ability to participate in any activity. If complete independence was not reached in each item of IADL, it was regarded as loss of function, and these items were calculated. In this study, both ADL and IADL were negatively correlated with depression, indicating that depression decreased with an increase in independence of the participants for ADL or IADL (ADL: $r=-0.479, p<0.01$; IADL: $r=-0.49, p<0.01$ ).

A significant negative correlation was observed between social support and depressive symptoms $(r=-0.506, p<0.01)$, demonstrating that the patients experienced fewer depressive symptoms when they received higher social support. A significant negative correlation was also found between RES and depressive symptoms $(r=-0.743, p<0.01)$. This finding indicated that the severity of depression decreased with improvement in the RES of the older patients.

\section{Buffering the severity of depression with demographic characteristics, symptom severity, ADLs, RES, and social support}

Table 4 presents the results of the multivariate analyses of the contribution of demographic characteristics, symptom severity, ADLs, and RES to the depressive symptoms of older patients. Gender, educational level, income source, major caregiver, and monthly allowance did not exert any buffering effect on depression. In Model 2, symptom severity positively affected the severity of depression (RES: $b=0.232$, $p<0.001)$ and RES buffered the severity of depression $(b=-0.596, p<0.001)$. ADL and IADL showed no effect in Model 2 with RES. These variables accounted for $62.3 \%$ of the variance in patient's depressive symptoms.

Table 5 lists the results of the multivariate analyses of the contribution of demographic characteristics, symptom severity, ADLs, and RES to the depressive symptoms of older patients. The depressive symptoms were positively affected by symptom severity $(b=0.277, p<0.01)$, ADL $(b=-0.201, p<0.01)$, and IADL $(b=-0.212, p<0.01)$ and negatively affected by social support $(b=-0.381, p<0.01)$. These variables accounted for $54.9 \%$ of the variance in depressive symptoms of the patients (Table 5). To examine whether RES and social support buffered the effects of demographic characteristics, symptom severity, ADLs, and depressive symptoms, multifactorial models were tested. The test of three interactions (among symptom severity, ADLs, and the use of RES and social support) revealed one significant buffering effect (Model 3 in Tables 4 and 5). The use of RES $(b=-0.436, p<0.01)$ was found to exert a significant buffering effect on the severity of patients' depressive symptoms. However, the use of social support

Table 3 Correlations between illness, physical symptoms, activities of daily living, resilience, social support, and depression ( $\mathrm{N}=194)$

\begin{tabular}{|c|c|c|c|c|c|c|c|}
\hline Variable & Illness & $\begin{array}{l}\text { Duration } \\
\text { of HD }\end{array}$ & Phy. Sym. & ADL & IADL & RES & SS \\
\hline \multicolumn{8}{|l|}{ Illness } \\
\hline Duration of HD & $-0.206 * *$ & & & & & & \\
\hline Phy. Sym. & $0.159 *$ & $0.187^{* *}$ & & & & & \\
\hline$A D L$ & -0.099 & 0.017 & $-0.161 *$ & & & & \\
\hline IADL & $-0.174 *$ & 0.067 & -0.138 & $0.644^{* *}$ & & & \\
\hline RES & -0.105 & 0.030 & $-0.262 * *$ & $0.549 * *$ & $0.556 * *$ & & \\
\hline SS & -0.029 & 0.040 & $-0.177^{*}$ & $0.184 *$ & $0.176^{*}$ & $0.417 * *$ & \\
\hline Dep. & 0.085 & 0.004 & $0.420 * *$ & $-0.479 * *$ & $-0.490 * *$ & $-0.743 * *$ & $-0.506 * *$ \\
\hline
\end{tabular}

Notes: $* p<0.05, * * p<0.01$. Statistical method: Pearson's correlation coefficient.

Abbreviations: ADL, activities of daily living; Dep., depression; HD, hemodialysis; IADL, instrumental activities of daily living; Phy. Sym., physical symptoms; RES, resilience; SS, social support. 
Table 4 Buffering effects of RES on the severity of depression according to demographics, symptom severity, and ADLs (N=I94)

\begin{tabular}{|c|c|c|c|c|c|c|}
\hline \multirow[t]{2}{*}{ Variable } & \multicolumn{2}{|c|}{ Model I } & \multicolumn{2}{|l|}{ Model 2} & \multicolumn{2}{|l|}{ Model 3} \\
\hline & $\boldsymbol{b}$ & SE & $b$ & SE & $\boldsymbol{b}$ & SE \\
\hline \multicolumn{7}{|l|}{ Elder demographics } \\
\hline Gender & -0.120 & 1.435 & -0.057 & 0.948 & -0.068 & 0.940 \\
\hline Education & -0.103 & 1.534 & -0.034 & 1.009 & -0.060 & 1.000 \\
\hline Income source & 0.038 & 1.547 & -0.006 & 1.018 & -0.003 & 0.998 \\
\hline Major caregiver & 0.135 & I.77I & -0.015 & 1.222 & -0.006 & 1.199 \\
\hline Monthly allowance & -0.107 & 1.494 & -0.011 & 1.010 & -0.012 & 0.991 \\
\hline \multicolumn{7}{|l|}{ Illness } \\
\hline Symptom severity & & & $0.232 * * *$ & 0.126 & $0.627 * * *$ & 0.370 \\
\hline \multicolumn{7}{|l|}{ Daily living activity } \\
\hline ADL & & & -0.061 & 0.032 & -0.156 & 0.077 \\
\hline IADL & & & -0.085 & 0.077 & 0.240 & 0.273 \\
\hline RES & & & $-0.596 * * *$ & 0.018 & $-0.595^{* * *}$ & 0.018 \\
\hline \multicolumn{7}{|l|}{ Interactions } \\
\hline $\mathrm{ADL} \times \mathrm{RES}$ & & & & & 0.116 & 0.001 \\
\hline IADL $\times$ RES & & & & & -0.355 & 0.003 \\
\hline Symptom severity $\times$ RES & & & & & $-0.436 * *$ & 0.004 \\
\hline Model $R^{2}$ & \multicolumn{2}{|c|}{0.088} & \multicolumn{2}{|c|}{0.623} & \multicolumn{2}{|c|}{0.644} \\
\hline$\Delta R^{2}$ & \multicolumn{2}{|c|}{0.088} & \multicolumn{2}{|c|}{0.535} & \multicolumn{2}{|c|}{0.021} \\
\hline$\Delta F$ & \multicolumn{2}{|c|}{$3.631 * *$} & \multicolumn{2}{|c|}{$65.159 * * *$} & \multicolumn{2}{|c|}{$3.633^{*}$} \\
\hline
\end{tabular}

Note: $* p<0.05, * * p<0.01, * * * p<0.001$.

Abbreviations: $A D L$, activities of daily living; IADL, instrumental activities of daily living; RES, resilience; SE, standard error.

Table 5 Buffering effects of SS on the severity of depression according to demographics, symptom severity, and ADLs (N=194)

\begin{tabular}{|c|c|c|c|c|c|c|}
\hline \multirow[t]{2}{*}{ Variable } & \multicolumn{2}{|c|}{ Model I } & \multicolumn{2}{|l|}{ Model 2} & \multicolumn{2}{|l|}{ Model 3} \\
\hline & $\beta$ & SE & $b$ & SE & $b$ & SE \\
\hline \multicolumn{7}{|l|}{ Elder demographics } \\
\hline Gender & -0.12 & 1.435 & -0.067 & 1.039 & -0.064 & 1.036 \\
\hline Education & -0.103 & 1.534 & -0.004 & 1.104 & -0.009 & 1.110 \\
\hline Income source & 0.038 & 1.547 & 0.059 & 1.118 & 0.058 & 1.116 \\
\hline Major caregiver & 0.135 & 1.771 & 0.051 & 1.357 & 0.053 & 1.359 \\
\hline Monthly allowance & -0.107 & 1.494 & -0.058 & 1.091 & -0.059 & 1.094 \\
\hline \multicolumn{7}{|l|}{ Illness } \\
\hline Symptom severity & & & $0.277 * *$ & 0.136 & $0.266 * * *$ & 0.137 \\
\hline \multicolumn{7}{|l|}{ Daily living activity } \\
\hline$A D L$ & & & $-0.201 * *$ & 0.033 & -0.137 & 0.037 \\
\hline IADL & & & $-0.212 * *$ & 0.082 & $-0.242 * *$ & 0.083 \\
\hline SS & & & $-0.38 I * *$ & 0.054 & $-0.374 * * *$ & 0.055 \\
\hline \multicolumn{7}{|l|}{ Interactions } \\
\hline $\mathrm{ADL} \times \mathrm{SS}$ & & & & & 0.098 & 0.003 \\
\hline $\mathrm{IADL} \times \mathrm{SS}$ & & & & & -0.036 & 0.008 \\
\hline Symptom severity $\times$ SS & & & & & -0.069 & 0.014 \\
\hline Model $R^{2}$ & \multicolumn{2}{|c|}{0.088} & \multicolumn{2}{|c|}{0.549} & \multicolumn{2}{|c|}{0.560} \\
\hline$\Delta R^{2}$ & \multicolumn{2}{|c|}{0.088} & \multicolumn{2}{|c|}{0.461} & \multicolumn{2}{|c|}{0.011} \\
\hline$\Delta F$ & \multicolumn{2}{|c|}{$3.63 I^{* *}$} & \multicolumn{2}{|c|}{$46.965 * * *$} & \multicolumn{2}{|c|}{1.496} \\
\hline
\end{tabular}

Note: $* * p<0.0$ I, $* * * p<0.001$

Abbreviations: ADL, activities of daily living; IADL, instrumental activities of daily living; SS, social support. 
was not observed to exert a significant buffering effect on the severity of depressive symptoms.

\section{Discussion}

The results of this study showed that among patients receiving maintenance HD, the severity of depressive symptoms was lower in men and in those with higher incomes and economic independence. The patients with higher RES had less severe depressive symptoms. The limitation of active and inactive daily activity worsened the depressive symptoms, and higher RES mitigated the severity of depressive symptoms.

In this study, depressive symptoms were higher in older women undergoing HD than in older men. This result is similar to that reported in other studies. ${ }^{40,41}$ In addition to genetic and cognitive factors, women experience more negative events compared with men during development, and men have more resources to deal with difficulties in daily life compared with women. ${ }^{42}$ A study proposed that testosterone concentration negatively correlates with depressive symptoms. ${ }^{43}$ In the current study, patients receiving monthly allowances of $>$ NT $\$ 30,000$ experienced fewer depressive symptoms than those receiving monthly allowances of $<\mathrm{NT} \$ 30,000$. Economic condition was associated with the severity of depressive symptoms. According to Pei and Pillai, ${ }^{44}$ the culture and social welfare system differs between Eastern and Western countries. In the Chinese society, older people receive more financial support from their own children, rather than from the social welfare system. A higher monthly allowance is related to higher family support (financial or emotional).

The severity of physical symptoms during HD was correlated with the severity of depression in our study. In addition, both ADL and IADL were negatively correlated with depression. Among physical symptoms in patients receiving HD, other studies conducted in Taiwan have reported that fatigue and weakness are more frequently observed and most substantially affect the daily life of patients; moreover, fatigue was negatively correlated with patient's ADL and IADL. ${ }^{15,45,46}$ Among patients who receive HD, fatigue results from multiple complications of renal failure, such as renal anemia, malnutrition-inflammation complex, intradialytic or interdialytic hypotension, and accumulation of a uremic toxin; in addition, fatigue causes limitations in daily activities. ${ }^{47,48}$ Because fatigue affects patients' ability to perform daily activities, a decrease in ADL or IADL is correlated with more severe depression. ${ }^{49,50}$ Depression has been associated with major cardiovascular events in both older adults who receive and do not receive HD, and the dysregulation of hormones may be the cause..$^{51,52}$ Therefore, patients receiving HD who experience physical symptoms and associated depressive mood may have poorer clinical outcomes. Interventions for alleviating physical symptoms and fatigue, such as treating renal complications or providing social support, should be provided in a timely manner.

In our study, we found that RES correlated positively with ADL and IADL and negatively with depression; hierarchical regression analysis demonstrated that RES exerted a buffering effect on the severity of depression. As an indicator of the ability to adapt and recover from the stress, RES is important for preventing the recurrence of depression during the recovering phase. ${ }^{53}$ Pre-dialysis education program has been practiced since 2006 in Taiwan, and the cost of predialysis education was covered by the National Insurance of Health. The multidisciplinary pre-dialysis provided the patients essential understanding about the renal replacement therapy and decreased the complications during or after the initiation of renal replacement therapy. ${ }^{54,55}$ Besides lessening the medical expenditure, the pre-ESRD education provided the patients the RES for confronting the psychiatric stress during therapy. Our previous study also provided evidence that the health-promoting behavior in the pre-ESRD stage augmented the RES. ${ }^{32}$ In patients who received renal replacement therapy, the modality and the illness restricted their daily routine in many aspects. ${ }^{56}$ Such restriction makes patients feel that they are losing their freedom, and they thus develop low self-esteem. Higher RES helps patients to confront their mental stress during therapy. ${ }^{24}$ It has also been suggested that pre-ESRD self-management program improves the severity of depression as well as other physical parameters. ${ }^{57}$ Based on the above aspects, establishing better RES at the pre-ESRD stage is crucial for patients to confront their illness, and it helps them to relieve depression after entering the ESRD stage.

In our study, social support did not exert a buffering effect on depression; this finding was inconsistent with its effect on patients with CKD or ESRD in previous studies. ${ }^{58,59}$ Social support was provided by family members, friends, and other members of an individual's surroundings. ${ }^{60}$ The expenditure for HD differs between countries. ${ }^{61}$ In Taiwan, the HD expenditure is covered by the National Insurance Health System. Patients receiving HD qualify as having a severe health disorder. ${ }^{62}$ The policy offers every citizen nearly equal financial access to comprehensive health services and provides all citizens with financial risk protection from large medical expenses. ${ }^{63}$ However, the social support didn't mitigate depression in 
our study. The National Health Insurance coverage reduces the financial burden of patients receiving HD. However, the depression-related complications, such as suicide death, even increased in ESRD patients in Taiwan. ${ }^{64}$ Eighty-three percent of the participants in our study had monthly allowances of $<$ NT\$30,000. According to a previous epidemiologic study, low socioeconomic status was a risk factor for mortality for ESRD in Taiwan. ${ }^{65}$ The perception of social support among older adults correlated with their social interaction, and it might explain partially the effect of alleviating depression in elderly ESRD patients. ${ }^{66}$ The more important part was the lower socioeconomic status of the individuals. Lower socioeconomic status lessens the effect of the social support and the patient's own awareness for the illness. ${ }^{67,68}$ In contrast to the Western society, the family structure in Taiwan is mainly kinship; therefore, the quality of family support, rather than that of emotional social support, influences patient's physical and emotional well-being. Based on the reasons above, the buffering effect of social support on stress or depression was not significant in the elderly ESRD patients in our study.

There are still several limitations in this cross-sectional study. First, the participants (194 older patients receiving HD) in this study were conveniently recruited from three hospitals in northern Taiwan; the sampling selection strategy might limit generalization of results. To overcome this limitation, future studies should consider employing randomized sampling and a time-series design. Besides, $63.4 \%$ of our participants had symptoms of itch. Uremic pruritis or itch feeling is an important issue in the ESRD patients. Based on the recent report from Dialysis Outcomes and Practice Patterns Study, the prevalence of itch feeling was around $18 \%-28 \% .{ }^{69}$ The percentage of itch feeling was higher in our study group. But the authors also mentioned that the prevalence might be underestimated. Because treatment of uremic pruritis includes antihistamine and gabapentine, which might influence the neuromuscular stability, the itch and muscle weakness might correlate. But further validation is needed. ${ }^{70}$ Moreover, to better understand various RES traits and explore psychosocial problems of older patients receiving $\mathrm{HD}$, open-ended interviews or related qualitative studies are further suggested.

\section{Conclusion}

The results of this study showed that the severity of depressive symptoms was lower in men and in patients with a higher income and economic independence. Patients with higher RES had less severe depressive symptoms. The limitation of active and inactive daily activity worsened depressive symptoms, and higher RES mitigated the severity of depressive symptoms. Hence, enhancing RES and social support for older patients receiving HD through establishing positive thinking or cognition should be emphasized in clinical or home settings.

\section{Acknowledgments}

We acknowledge the commitment and dedication of the study investigators at Cardinal Tien Hospital, Taipei University of Nursing, and Fu-Jen Catholic University. The clinical trial was funded by CTH-104-1-2A05 for data collection, analysis, and the preparation of the study report and manuscript.

\section{Author contributions}

$\mathrm{KCL}, \mathrm{HJC}$, and RHW conceived and designed the experiments; YML performed the experiments and analyzed the data; LKY contributed analysis tools; and YCH and YML wrote the paper. All authors contributed toward data analysis, drafting and revising the paper and agree to be accountable for all aspects of the work.

\section{Disclosure}

The authors report no conflicts of interest in this work.

\section{References}

1. Taiwan Chronic Kidney Disease Clinical Guidelines; 2015. Available from: www.tsn.org.tw/UI/H/H00202.aspx. Accessed October 9, 2017.

2. 2015. The National Health Insurance Annual Statistical Reports; 2015. Available from: http://www.mohw.gov.tw/MOHW_Upload/doc/104\% E6\%8C\%87\%E6\%A8\%99\%E8\%A6\%81\%E8\%A6\%BD_0000674001. pdf. Accessed October 9, 2017.

3. Kao TW, Chang YY, Chen PC, et al. Lifetime costs for peritoneal dialysis and hemodialysis in patients in Taiwan. Perit Dial Int. 2013; 33(6):671-678.

4. Yong DS, Kwok AO, Wong DM, Suen MH, Chen WT, Tse DM. Symptom burden and quality of life in end-stage renal disease: a study of 179 patients on dialysis and palliative care. Palliat Med. 2009; 23(2):111-119.

5. Kao TW, Lai MS, Tsai TJ, Jan CF, Chie WC, Chen WY. Economic, social, and psychological factors associated with health-related quality of life of chronic hemodialysis patients in northern Taiwan: a multicenter study. Artif Organs. 2009;33(1):61-68.

6. Lemos CF, Rodrigues MP, Veiga JR. Family income is associated with quality of life in patients with chronic kidney disease in the predialysis phase: a cross sectional study. Health Qual Life Outcomes. 2015; 13:202.

7. Santoro D, Ingegnieri MT, Vita G, et al. Socio-economic factors, food habits and phosphorus levels in patients on hemodialysis. Nephrourol Mon. 2015;7(4):e27114.

8. Prasad N, Jha V. Hemodialysis in Asia. Kidney Dis (Basel). 2015;1(3): $165-177$.

9. Chen SF, Wang IJ, Lang HC. Risk of major depression in patients with chronic renal failure on different treatment modalities: a matchedcohort and population-based study in Taiwan. Hemodial Int. 2016; 20(1):98-105. 
10. Bai YL, Lai LY, Lee BO, Chang YY, Chiou CP. The impact of depression on fatigue in patients with haemodialysis: a correlational study. J Clin Nurs. 2015;24(13-14):2014-2022.

11. Sims J, Bennett PN, Ockerby C, et al. The effect of holiday haemodialysis treatments on patient mood, adverse symptoms and subjective wellbeing using the Big Red Kidney Bus. Nephrology (Carlton). 2016; 22(2):107-113.

12. Osthus TB, von der Lippe N, Ribu L, et al. Health-related quality of life and all-cause mortality in patients with diabetes on dialysis. $B M C$ Nephrol. 2012;13:78.

13. Zalai D, Szeifert L, Novak M. Psychological distress and depression in patients with chronic kidney disease. Semin Dial. 2012;25(4): $428-438$.

14. Abdel-Kader K, Unruh ML, Weisbord SD. Symptom burden, depression, and quality of life in chronic and end-stage kidney disease. Clin J Am Soc Nephrol. 2009;4(6):1057-1064.

15. Bossola M, Di Stasio E, Antocicco M, Panico L, Pepe G, Tazza L. Fatigue is associated with increased risk of mortality in patients on chronic hemodialysis. Nephron. 2015;130(2):113-118.

16. Racic M, Petkovic N, Bogicevic K, et al. Comprehensive geriatric assessment: comparison of elderly hemodialysis patients and primary care patients. Ren Fail. 2015;37(7):1126-1131.

17. Chilcot J, Wellsted D, Silva-Gane D, Farrington K. Depression on dialysis. Nephron Clin Pract. 2008;108(4):c256-c264.

18. Finkelstein FO, Finkelstein SH. Depression in chronic dialysis patients: assessment and treatment. Nephrol Dial Transplant. 2000;15(12): 1911-1913

19. Turkmen K, Erdur FM, Guney I, et al. Sleep quality, depression, and quality of life in elderly hemodialysis patients. Int J Nephrol Renovasc Dis. 2012;5:135-142.

20. Hedayati SS, Bosworth HB, Briley LP, et al. Death or hospitalization of patients on chronic hemodialysis is associated with a physician-based diagnosis of depression. Kidney Int. 2008;74(7):930-936.

21. Wagnild G, Young H. Development and psychometric evaluation of the resilience scale. J Nurs Meas. 1993;1(2):165-178.

22. Windle G. What is resilience? A review and concept analysis. Rev Clin Gerontol. 2011;21(2):152-169.

23. Lin CC, Liang CC, Huang FL, Lai LH. Relationships between hope and social support of hemodialysis patients. J Taiwan Nephrol Nur Association. 2004;3(1):17-31.

24. Ozbay F, Johnson DC, Dimoulas E, Morgan CA, Charney D, Southwick S. Social support and resilience to stress: from neurobiology to clinical practice. Psychiatry (Edgmont). 2007;4(5):35-40.

25. Lin N, Simeone RS, Ensel WM, Kuo W. Social support, stressful life events, and illness: a model and an empirical test. J Health Social Behav. 1979;20(2):108-119.

26. Kimmel PL, Emont SL, Newmann JM, Danko H, Moss AH. ESRD patient quality of life: symptoms, spiritual beliefs, psychosocial factors, and ethnicity. Am J Kidney Dis. 2003;42(4):713-721.

27. Penninx BW, van Tilburg T, Boeke AJ, Deeg DJ, Kriegsman DM, van Eijk JT. Effects of social support and personal coping resources on depressive symptoms: different for various chronic diseases? Health Psychol. 1998;17(6):551-558.

28. Plaisier I, de Bruijn JG, de Graaf R, ten Have M, Beekman AT, Penninx BW. The contribution of working conditions and social support to the onset of depressive and anxiety disorders among male and female employees. Social Sci Med. 2007;64(2):401-410.

29. Jeste DV, Savla GN, Thompson WK, et al. Association between older age and more successful aging: critical role of resilience and depression. Am J Psychiatry. 2013;170(2):188-196.

30. Rutter M. Annual research review: resilience-clinical implications. J Child Psychol Psychiatry. 2013;54(4):474-487.

31. Hjemdal O, Friborg O, Stiles TC, Rosenvinge JH, Martinussen M. Resilience predicting psychiatric symptoms: a prospective study of protective factors and their role in adjustment to stressful life events. Clin Psychol Psychother. 2006;13:194-201.
32. Ma LC, Chang HJ, Liu YM, et al. The relationship between healthpromoting behaviors and resilience in patients with chronic kidney disease. ScientificWorldJournal. 2013;2013:124973.

33. Malhotra C, Chan A, Matchar D, Seow D, Chuo A, Do YK. Diagnostic performance of short portable mental status questionnaire for screening dementia among patients attending cognitive assessment clinics in Singapore. Ann Acad Med Singapore. 2013;42(7):315-319.

34. Chen ML, Ku NP. Factors associated with quality of life among patients on hemodialysis. Nurs Res. 1998;6(5):393-404.

35. Hsu SM, Chiou CJ. [An exploratory study of primary family caregivers' needs and factors in their interaction with home care nurses]. Hu $\mathrm{Li} \mathrm{Za}$ Zhi. 2004;51(5):53-60. Chinese.

36. Chuang YF, Lin L, Sung HC. Health status and health resource utilization among older people in rural mining area. Tzu Chi Nursing J. 2005;4(1):34-41. Chinese.

37. Li M-H. Relationships among stress coping, secure attachment, and the trait of resilience among Taiwanese college students. College Student J. 2008;42(2):312-325.

38. Ahern NR, Kiehl EM, Sole ML, Byers J. A review of instruments measuring resilience. Issues Compr Pediatr Nurs. 2006;29(2):103-125.

39. Tseng H. Social support and hope status of patients with depression in out-patient department. Unpublished master's thesis in Chinese. Kaohsiung Medical University, Kaohsiung, Taiwan; 1999.

40. Armaly Z, Farah J, Jabbour A, et al. Major depressive disorders in chronic hemodialysis patients in Nazareth: identification and assessment. Neuropsychiatric DisTreat. 2012;8:329-338.

41. Njah M, Nasr M, Ben Dhia N. [Anxiety and depression in the hemodialysis patient]. Nephrologie. 2001;22(7):353-357. French.

42. Hankin BL, Abramson LY. Development of gender differences in depression: Description and possible explanations. Ann Med. 1999; 31(6):372-379.

43. Kessler RC, Berglund P, Demler O, et al. The epidemiology of major depressive disorder: results from the National Comorbidity Survey Replication (NCS-R). JAMA. 2003;289(23):3095-3105.

44. Pei X, Pillai VK. Old age support in China: The role of the state and the family. Int J Aging Hum Dev. 1999;49(3):197-212.

45. Kavanagh NT, Schiller B, Saxena AB, Thomas I, Kurella Tamura M. Prevalence and correlates of functional dependence among maintenance dialysis patients. Hemodial Int. 2015;19(4):593-600.

46. Hardy SE, Concato J, Gill TM. Resilience of community-dwelling older persons. J Am Geriatr Soc. 2004;52(2):257-262.

47. Chao CT, Huang JW, Chiang CK; COGENT (COhort of GEriatric Nephrology in NTUH) study group. Functional assessment of chronic illness therapy-the fatigue scale exhibits stronger associations with clinical parameters in chronic dialysis patients compared to other fatigue-assessing instruments. PeerJ. 2016;4:e1818.

48. Wang SY, Zang XY, Fu SH, et al. Factors related to fatigue in Chinese patients with end-stage renal disease receiving maintenance hemodialysis: a multi-center cross-sectional study. Ren Fail. 2016;38(3):442-450.

49. Bugalho P, Lampreia T, Miguel R, Mendonca MD, Caetano A, Barbosa R. Non-motor symptoms in Portuguese Parkinson's disease patients: correlation and impact on quality of life and activities of daily living. Sci Rep. 2016;6:32267.

50. van de Port IG, Kwakkel G, Schepers VP, Heinemans CT, Lindeman E. Is fatigue an independent factor associated with activities of daily living, instrumental activities of daily living and health-related quality of life in chronic stroke? Cerebrovasc Dis. 2007;23(1):40-45.

51. Gilles M, Scharnholz B, Marzina A, et al. Increased left ventricular mass in hypercortisolemic depressed patients: a hypothesis based on a case series. Med Hypotheses. 2014;83(6):730-732.

52. Sampaio LA, Fraguas R, Lotufo PA, Bensenor IM, Brunoni AR. A systematic review of non-invasive brain stimulation therapies and cardiovascular risk: implications for the treatment of major depressive disorder. Front Psychiatry. 2012;3:87.

53. Waugh CE, Koster EH. A resilience framework for promoting stable remission from depression. Clin Psychol Rev. 2015;41:49-60. 
54. Hsieh HM, Lin MY, Chiu YW, et al. Economic evaluation of a preESRD pay-for-performance programme in advanced chronic kidney disease patients. Nephrol Dial Transplant. 2017;32(7):1184-1194.

55. Yu YJ, Wu IW, Huang CY, et al. Multidisciplinary predialysis education reduced the inpatient and total medical costs of the first 6 months of dialysis in incident hemodialysis patients. PLoS One. 2014;9(11): e112s 820 .

56. Tong A, Henning P, Wong G, et al. Experiences and perspectives of adolescents and young adults with advanced CKD. Am J Kidney Dis. 2013;61(3):375-384.

57. Wu SFV, Lee MC, Hsieh NC, Lu KC, Tseng HL, Lin LJ. Effectiveness of an innovative self-management intervention on the physiology, psychology, and management of patients with pre-end-stage renal disease in Taiwan: a randomized, controlled trial. Jpn J Nurs Sci. Epub 2017 Dec 20.

58. Chan KY, Yip T, Yap DY, et al. Enhanced psychosocial support for caregiver burden for patients with chronic kidney failure choosing not to be treated by dialysis or transplantation: a pilot randomized controlled trial. Am J Kidney Dis. 2016;67(4):585-592.

59. Khalil AA, Abed MA. Perceived social support is a partial mediator of the relationship between depressive symptoms and quality of life in patients receiving hemodialysis. Arch Psychiatr Nurs. 2014;28(2): 114-118.

60. Zimet GD, Dahlem NW, Zimet SG, Farley GK. The multidimensional scale of perceived social support. J Pers Assess. 1988;52(1):30-41.

61. USRDS Annual data report: Chapter twelve international comparisons 2013; 2015. Availabel from: http://www.usrds.org/2011/pdf/ v2_ch012_11.pdf. Accessed November 14, 2012.
62. Chen L, Yip W, Chang MC, et al. The effects of Taiwan's National Health Insurance on access and health status of the elderly. Health Econ. 2007;16(3):223-242.

63. Ho Chan WS. Taiwan's healthcare report 2010. EPMA J. 2010;1(4): $563-585$.

64. Chen IM, Lin PH, Wu VC, et al. Suicide deaths among patients with end-stage renal disease receiving dialysis: a population-based retrospective cohort study of 64,000 patients in Taiwan. $J$ Affect Disord. 2017;227:7-10.

65. Wen CP, Cheng TYD, Tsai MK, et al. All-cause mortality attributable to chronic kidney disease: a prospective cohort study based on 462293 adults in Taiwan. Lancet. 2008;371(9631):2173-2182.

66. Lynch TR, Mendelson T, Robins CJ, et al. Perceived social support among depressed elderly, middle-aged, and young-adult samples: crosssectional and longitudinal analyses. J Affect Disord. 1999;55(2-3): $159-170$.

67. Ng CW, Tan WS, Gunapal PP, Wong LY, Heng BH. Association of Socioeconomic Status (SES) and social support with depressive symptoms among the Elderly in Singapore. Ann Acad Med Singapore. 2014;43(12):576-587.

68. Vonneilich N, Jöckel K-H, Erbel R, et al. Does socioeconomic status affect the association of social relationships and health? A moderator analysis. Int J Equity Health. 2011;10(1):43.

69. Rayner HC, Larkina M, Wang M, et al. International comparisons of prevalence, awareness, and treatment of pruritus in people on hemodialysis. Clin J Am Soc Nephrol. 2017;12(12):2000-2007.

70. Germain MJ. Uremic pruritus: an itch with ominous consequences. Am J Nephrol. 2017;46(6):448-449.
Therapeutics and Clinical Risk Management

\section{Publish your work in this journal}

Therapeutics and Clinical Risk Management is an international, peerreviewed journal of clinical therapeutics and risk management, focusing on concise rapid reporting of clinical studies in all therapeutic areas, outcomes, safety, and programs for the effective, safe, and sustained use of medicines. This journal is indexed on PubMed Central, CAS,

\section{Dovepress}

EMBase, Scopus and the Elsevier Bibliographic databases. The manuscript management system is completely online and includes a very quick and fair peer-review system, which is all easy to use. Visit http://www.dovepress.com/testimonials.php to read real quotes from published authors.

Submit your manuscript here: http://www.dovepress.com/therapeutics-and-clinical-risk-management-journal 